\title{
Implementation Example of the Expert system for Decision Support on Android platform based on a specific Dataset
}

\author{
Muzafer Saračević ${ }^{1}$, Aybeyan Selimi ${ }^{2}$, Mersad Mujević ${ }^{3}$ \\ ${ }^{1}$ Department of Computer sciences, University of Novi Pazar, Serbia \\ ${ }^{2}$ Faculty of Informatics, International Vision University, Macedonia \\ ${ }^{3}$ Public Procurement Administration, Government of Montenegro
}

\section{Article Info}

Article history:

Received Dec $17^{\text {th }}, 2017$

Revised Mar $16^{\text {th }}, 2018$

Accepted Aprt 10 ${ }^{\text {th }}, 2018$

\section{Keyword:}

Expert systems

Decision Support

DataSet qualification problem

Model prediction

Android platforms

\section{Corresponding Author:}

Muzafer Saračević,

Department of Computer sciences,

University of Novi Pazar,

Dimitrija Tucovica bb, Novi Pazar, Serbia,

Email: muzafers@uninp.edu.rs

\begin{abstract}
This paper presents the method of creating Expert system for decision support on the Android platform. The system knowledge base for the given area of expertise is generated by inductive learning methods based on examples from the WEKA data research system. The system was realized using the Expert System shell for the $e 2 g$ Droid lite mobile device, based on the application area and a set of training examples, specifically based on the Covertype DataSet qualification problem.
\end{abstract}

\section{Introduction}

The main task of the Covertype Data Set qualification problem is to predict forest cover type only with cartographic signs, without other data. Independent variables are derived from data originally obtained from the US Geological Survey - USGS and US Forest Service - USFS. This research includes four wild regions ie areas, located in the Roosevelt National Forest north of Colorado. Some basic information for these four regions are:

1. Rawah (region 1)

2. Neota (region 2), probably has the highest altitude,

3. Comanche Peak (region 3) have a lower altitude than region 2,

4. Cashe la Poudre (region 4) has the lowest altitude.

As for the types of trees in this area: in Neot, the most common spruce / firs (type 1), while in Rawah and Comanche Peak is the most abundant twisted pine (type 2) as the main species, then spruce / fir and aspen (type 5) . In Cache la Poudre there are red pine (type 3), Douglas fir (type 6), and poplar / willow (type 4). The areas of Rawah and Comanche Peak tend to be more typical when looking at data than Neota or Cache la Poudre, precisely because of the diversity of tree species and the range of predictable values of variables such as altitude. Cache la Poudre is more unique than others due to less altitude value and species diversity. 
In addition to four regions, twelve cartographic measures (independent variables) and seven types of large forest surfaces (dependent variables) are included. This set of data has 581,012 instances of which: the first 11,340 records are taken for view the data from a subset, the next 3,780 records are taken for data verification in subset, and the last 565,892 records are taken for test the data in the subsets [1].

Table 1. Basic characteristics of Covertype DataSet qualification problem

\begin{tabular}{|l|l|l|l|}
\hline Characteristics of data: & More variants & Number of instances: & 581012 \\
\hline Characteristics of attributes: & Cartographic, integers & Number of attributes: & 54 \\
\hline Assigned tasks: & Division, classification & Missing variables? & No \\
\hline
\end{tabular}

Managers of national parks responsible for management of for strategy of eco-system require basic information, including a list of earth reforestation inventories to make it easier for the decision-making process. One way of obtaining this information is model prediction.

In the papers $[2,3,4]$, two predictive models were examined: a model of a neural network and a traditional statistical model based on a discriminant analysis. The overall objectives of these studies are to develop these two predictive models [5], to compare and estimate their precision in the division of types of wood cover in unexplored (uninhabited) forests.

Several sub-sets of these variables have been tested for determining of the best predictive model $[6,7,8,9]$. For each subset of twelve cartographic variables, which were examined in studies, the relative classification indicates that the approach to the application of neural networks exceeds the traditional method of discriminatory analysis in predicting of the forest cover type. The final neural network model was more precise in the classification (70.58\%) than the linear regression model for prediction (58.38\%). In support of these results, there are thirty more networks with randomly selected initial results. The total mean value of the precision in split for the neural network model is $70.52 \%$.

Therefore, national park managers can use an alternative method in predicting of the forest cover type that is superior to the traditional method and adequate to support their decision-making process for the eco-system management strategy.

\section{Attributes and Classes for Covertype DataSet qualification problem}

The dataset consists of 54 attributes, 10 attribute values are from numerical type, while the Wilderness_Area type attributes values consists of 4 binary variables, and the Soil_Type values consist of 40 binary values. For Attribute information (name, type, unit of measurement, description) see UCI Machine Learning Repository: Covertype DataSet [1].

All examples are associated with one of the Class_Type qualification attributes, whose values can be numeric in the range from 1 to 7 , where each of numbers represents one of the classes ${ }^{1}$ :
1. Spruce/Fir
2. Lodgepole Pine
3. Ponderosa Pine
4. Cottonwood/Willow
5. Aspen
6. Douglas-fir
7. Krummholz.

Below are given the values of the first two samples:

- $2596,51,3,258,0,510,221,232,148,6279,1,0,0,0,0,0,0,0,0,0,0,0,0,0,0,0,0,0,0,0,0,0,0,0,0,0,0,0,0,0,0,0,1,0$, $0,0,0,0,0,0,0,0,0,0,5$

- $2590,56,2,212,6,390,220,235,151,6225,1,0,0,0,0,0,0,0,0,0,0,0,0,0,0,0,0,0,0,0,0,0,0,0,0,0,0,0,0,0,0,0,1,0$, $0,0,0,0,0,0,0,0,0,0,5$

\footnotetext{
${ }^{1}$ Standard names of classes from the given Covertype dataset which is used in other test cases and case studies
} 
Since Wilderness_Area and Soil_Type consist of mutually exclusive binary values, we can combine them, so from 4-binary attribute for Wilderness_Area we will obtain one attribute with a nominal value. In the same way, the Soil_Type with 40 binary attributes, we expire on one attribute with a nominal value. After this preprocessing, the attribute definitions in .arff format are given below (see Chart 1):

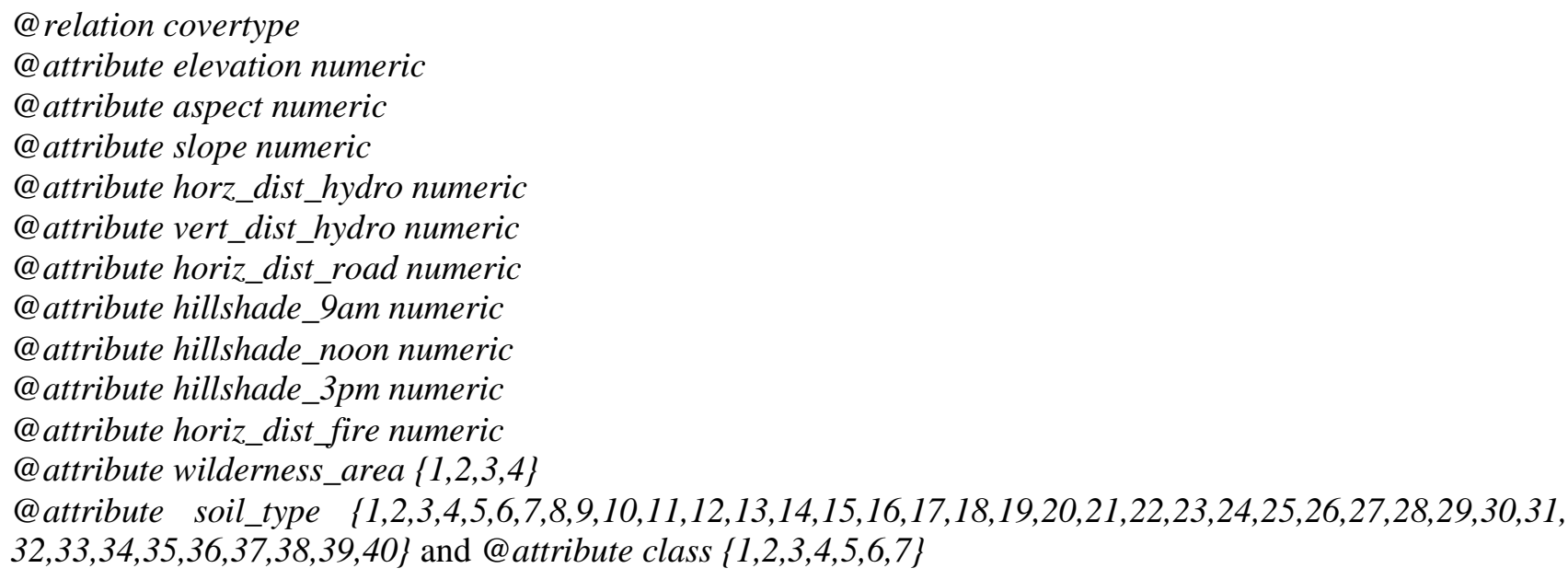

The values of the first two samples from the data set in the .arff format are given below:

- $\quad 2596,51,3,258,0,510,221,232,148,6279,1,29,5$

- $2590,56,2,212,-6,390,220,235,151,6225,1,29,5$.

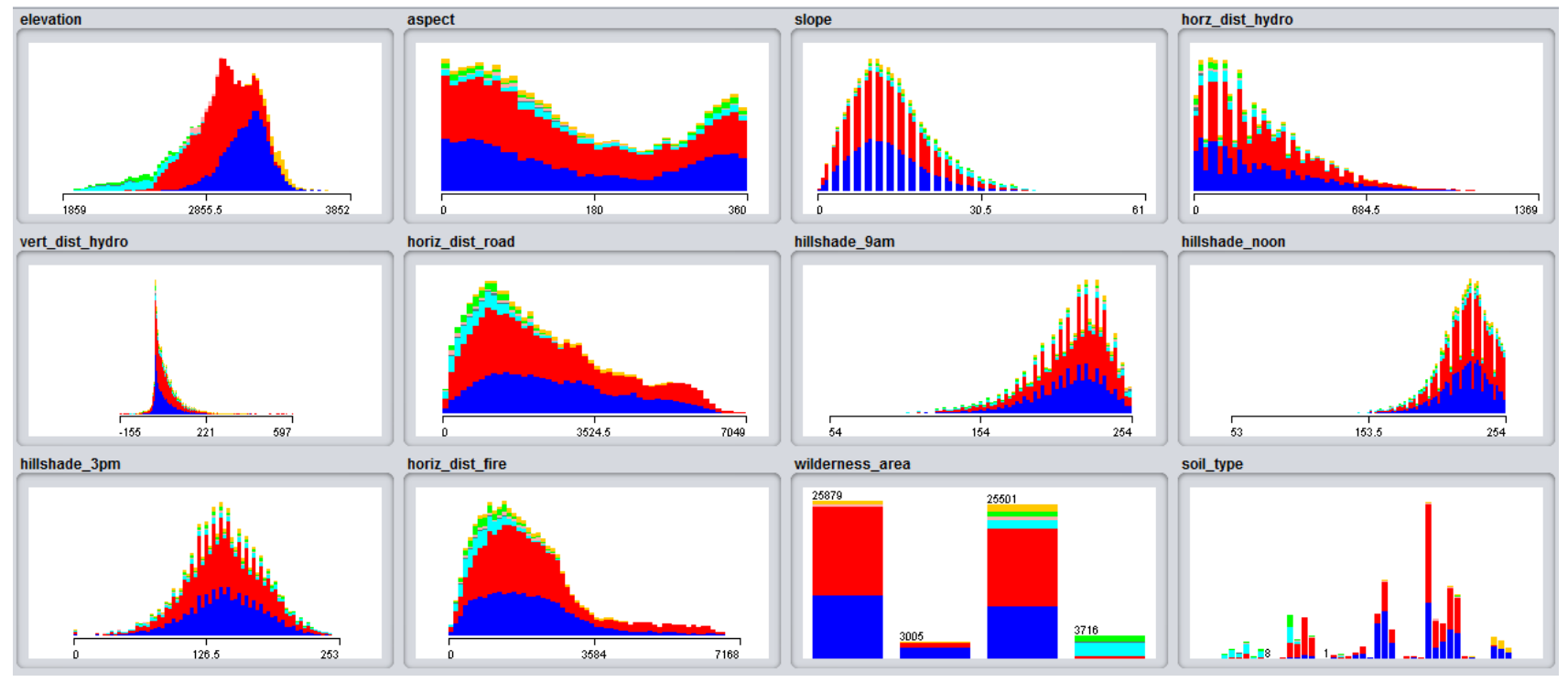

Chart 1. Visual representation of attribute distribution after preprocessing

Redistribution of examples by classes (see Table 2):

Table 2. Without "Resample" filter

\begin{tabular}{|l|l|l|}
\hline \multicolumn{1}{|c|}{ Classes } & \multicolumn{1}{c|}{ No. of samples } & \\
\hline Spruce-Fir & 211840 & \\
\hline Lodgepole Pine & 283301 & \\
\hline Ponderosa Pine & 35754 & \\
\hline Cottonwood/Willow & 2747 & \\
\hline Aspen & 9493 & \\
\hline Douglas-fir & 17367 & \\
\hline
\end{tabular}




\begin{tabular}{|l|l|l|}
\hline Krummholz & 20510 & $\square$ \\
\hline Total instances & $\mathbf{5 8 1 0 1 2}$ & \\
\hline
\end{tabular}

Redistribution after the application of unsupervised instances of the "Resample" filter, taking 10\% (see Table $3)$ :

Table 3. "Resample" filter

\begin{tabular}{|l|l|l|}
\hline \multicolumn{1}{|c|}{ Classes } & No. of samples & \\
\hline Spruce-Fir & 20885 & $\mathbf{}$ \\
\hline Lodgepole Pine & 28618 & $\mathbf{\square}$ \\
\hline Ponderosa Pine & 3611 & \\
\hline Cottonwood/Willow & 280 & \\
\hline Aspen & 922 & \\
\hline Douglas-fir & 1730 & \\
\hline Krummholz & 2055 & \\
\hline Total instances & $\mathbf{5 8 1 0 1}$ & \\
\hline
\end{tabular}

Next chart shows redistribution $\quad$ based $\quad$ on $\quad$ Table 3.

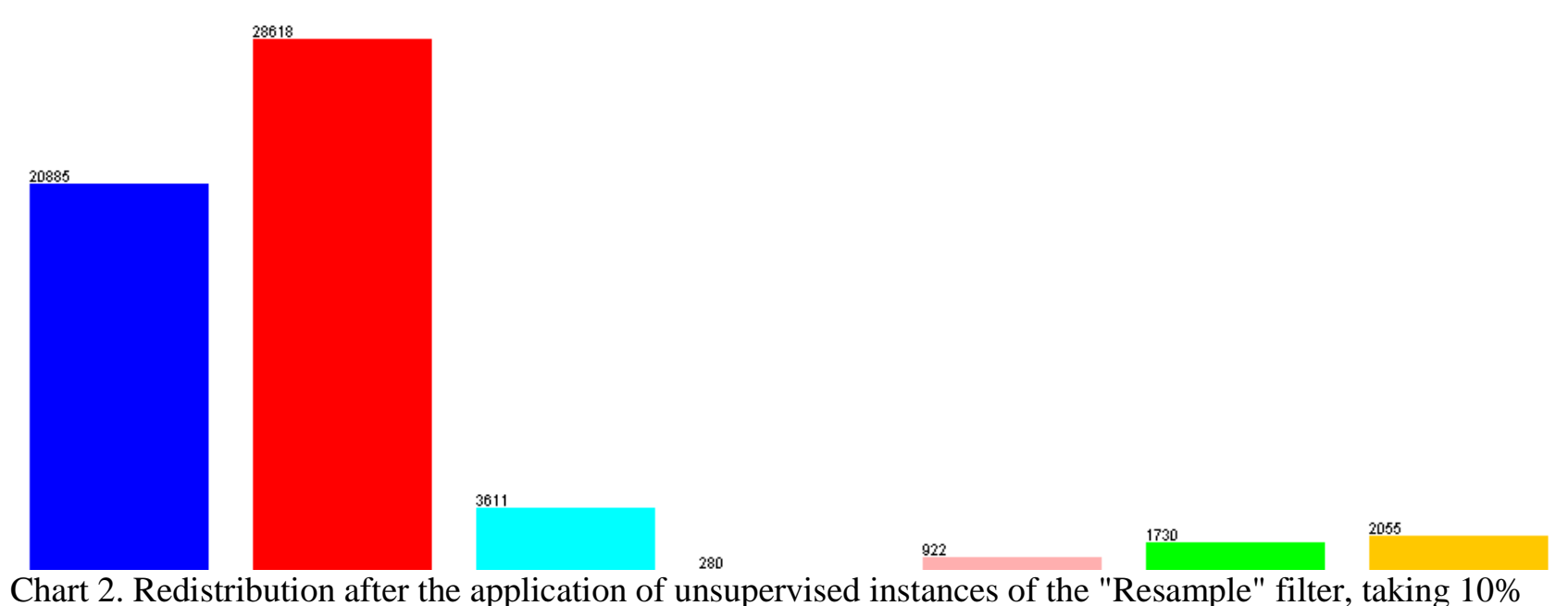

Chart 2. Redistribution after the application of unsupervised instances of the "Resample" filter, taking $10 \%$

\section{Learning outcomes and learned rules}

As can be seen from the previous section of this paper, after filtering with the unsupervised instance Resample filter, the number of instances is reduced to 58101, which is $10 \%$ of the total number of samples in the entire dataset. With using of the PART method, with the default parameters to the preprocessed dataset, we get 1760 learned rules.

The precision is checked by a 10 -fold cross-validation and we get that $84.29 \%$ is correctly classified. However, the number of rules is very high in order to be manually translated into a knowledge base for the expert system, so we must try to "tree pruning" by changing the parameters in the PART method:

- By increasing the parameter M (the minimum number of instances as a rule), we reduce the tree or the number of rules, since the data set is relatively large, we take $\mathrm{M}=1000$.

- We will also reduce the value of $\mathrm{C}$ (Confidence Factor) whose reduction we achieve a greater "tree pruning", we take the value $\mathrm{C}=0.15$ (default is 0.25 ).

- With these parameters we get 143 learned rules, and precision is $75.36 \%$, which is again a great number for manual translation into the knowledge base.

- By adjusting the parameters we will try to get a reasonable number of rules that we can manually translate into the knowledge base.

- After several attempts for different values of $\mathrm{M}$ and $\mathrm{C}$, we have come to an optimal solution where for the parameter values $\mathrm{M}=400$ and $\mathrm{C}=0.15$ we obtain a tree of 28 rules and a precision of $71.07 \%$. 


\subsection{Obtained learning rules}

Using the chosen method for learning of the production rules, PART from the WEKA data research system [10], is inductively learned set of the production rules. The accuracy and comprehensiveness of the learned knowledge is optimized with the available $\mathbf{M}$ and $\mathbf{C}$ parameters of the selected learning methods.

Table 4. PART decision list (only the first 17 rules)

\begin{tabular}{|c|c|c|}
\hline 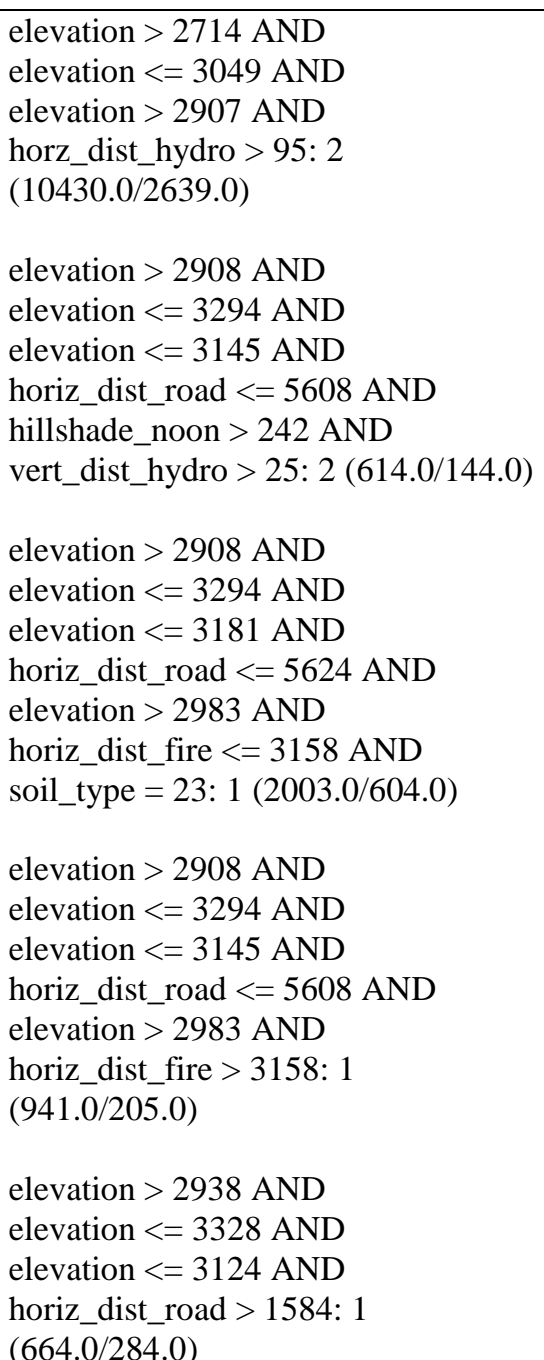 & $\begin{array}{l}\text { elevation > 2908 AND } \\
\text { elevation <= 3294 AND } \\
\text { elevation <= } 3139 \text { AND } \\
\text { horiz_dist_road <= 5624 AND } \\
\text { soil_type = 32: } 2 \text { (1164.0/413.0) } \\
\text { elevation > 2908 AND } \\
\text { elevation <= 3294 AND } \\
\text { horiz_dist_road > 5433 AND } \\
\text { horiz_dist_fire > 1090: } 2 \\
\text { (1277.0/353.0) } \\
\text { elevation > 2908 AND } \\
\text { elevation <= 3294 AND } \\
\text { elevation <= } 3181 \text { AND } \\
\text { elevation > 3067: } 1 \text { (5534.0/1819.0) } \\
\text { elevation > 2909 AND } \\
\text { elevation <= 3328 AND } \\
\text { elevation <= 3124 AND } \\
\text { horiz_dist_road <= 3543 AND } \\
\text { hillshade_noon <= 221: } 1 \\
\text { (800.0/265.0) } \\
\text { elevation > 2909 AND } \\
\text { elevation <= 3328 AND } \\
\text { elevation <= 3124 AND } \\
\text { elevation > 2955 AND } \\
\text { horiz_dist_road > 1734 AND } \\
\text { horiz_dist_road > 3632: } 2 \\
\text { (465.0/191.0) }\end{array}$ & $\begin{array}{l}\text { elevation > 3063 AND } \\
\text { elevation <= 3328 AND } \\
\text { soil_type }=23: 1(1394.0 / 350.0) \\
\text { elevation > 3063 AND } \\
\text { elevation <= 3328 AND } \\
\text { soil_type }=22: 1 \text { (1257.0/125.0) } \\
\text { elevation > 3063 AND } \\
\text { elevation > 3329 AND } \\
\text { wilderness_area = 1: } 1 \text { (886.0/236.0) } \\
\text { elevation > 3063 AND } \\
\text { elevation <= 3333 AND } \\
\text { soil_type = 33: } 1 \text { (1006.0/329.0) } \\
\text { elevation > 3066 AND } \\
\text { elevation <= 3328 AND } \\
\text { horiz_dist_road > 1127 AND } \\
\text { soil_type = 32: } 1 \text { (859.0/292.0) } \\
\text { elevation > 3066 AND } \\
\text { elevation > 3349 AND } \\
\text { horiz_dist_road <= 3517 AND } \\
\text { horiz_dist_fire <= 2016 AND } \\
\text { hillshade_3pm <= 157: } 7 \\
\text { (499.0/130.0) } \\
\text { elevation > 2668 AND } \\
\text { elevation <= 3066: } 2 \\
\text { (13171.0/3182.0) }\end{array}$ \\
\hline
\end{tabular}

Table 5. Obtained precision by classes

\begin{tabular}{|ccccccccc|}
\hline TP Rate & FP Rate & Precision & Recall & F-Measure & MCC & ROC Area & PRC Area & Class \\
\hline 0.677 & 0.160 & 0.704 & 0.677 & 0.690 & 0.521 & 0.830 & 0.715 & 1 \\
0.816 & 0.285 & 0.735 & 0.816 & 0.773 & 0.533 & 0.820 & 0.778 & 2 \\
0.759 & 0.031 & 0.618 & 0.759 & 0.681 & 0.662 & 0.969 & 0.637 & 3 \\
0.000 & 0.000 & 0.000 & 0.000 & 0.000 & 0.000 & 0.985 & 0.171 & 4 \\
0.000 & 0.000 & 0.000 & 0.000 & 0.000 & 0.000 & 0.858 & 0.058 & 5 \\
0.119 & 0.005 & 0.440 & 0.119 & 0.187 & 0.218 & 0.953 & 0.337 & 6 \\
0.422 & 0.009 & 0.638 & 0.422 & 0.508 & 0.505 & 0.968 & 0.533 & 7 \\
\hline $\mathbf{0 . 7 1 1}$ & $\mathbf{0 . 2 0 0}$ & $\mathbf{0 . 6 8 9}$ & $\mathbf{0 . 7 1 1}$ & $\mathbf{0 . 6 9 5}$ & $\mathbf{0 . 5 1 5}$ & $\mathbf{0 . 8 4 3}$ & $\mathbf{0 . 7 1 0}$ & \\
\hline
\end{tabular}


Precision represented as a confusion matrix:

$\begin{array}{rrrllrrll}\mathrm{a} & \mathrm{b} & \mathrm{c} & \mathrm{d} & \mathrm{e} & \mathrm{f} & \mathrm{g} & <- \text { classified as } \\ 14137 & 6280 & 16 & 0 & 0 & 0 & 452 & \mathrm{a}=1 \\ 4792 & 23344 & 389 & 0 & 0 & 53 & 40 & \mathrm{~b}=2 \\ 0 & 662 & 2740 & 0 & 0 & 209 & 0 & \mathrm{c}=3 \\ 0 & 0 & 280 & 0 & 0 & 0 & 0 & \mathrm{~d}=4 \\ 3 & 905 & 14 & 0 & 0 & 0 & 0 & \mathrm{e}=5 \\ 0 & 527 & 997 & 0 & 0 & 206 & 0 & \mathrm{f}=6 \\ 1162 & 26 & 0 & 0 & 0 & 0 & 867 & \mathrm{~g}=7\end{array}$

\section{View the functioning of the Expert system on Android Platforms and Web environment}

In creation a covtype.kb file with a total of 28 rules, is used the e2gRuleWriter tool. The learned set of rules was built into the knowledge base of the expert system e2gDroid Expert System. The user interface of the system in Serbian was created using the Expertise2Go translate directive. Below are given the demonstration of performance testing of a small expert system on some of the selected examples.

The first case of testing on Android Platforms (Figure 1) and second case of testing in web - HTML environment (Figure 2).
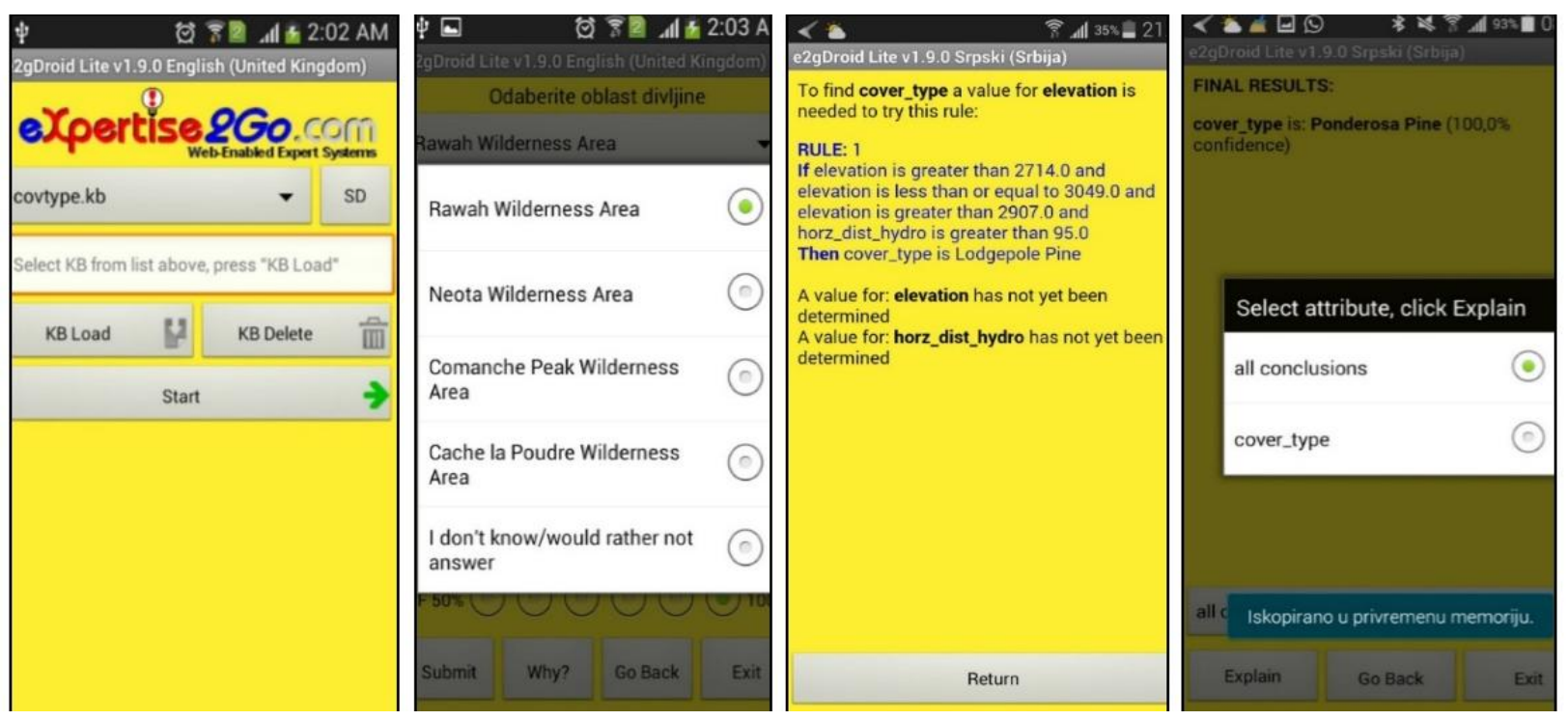

Figure 1. Some parts of an application that has been customized for Android Platforms

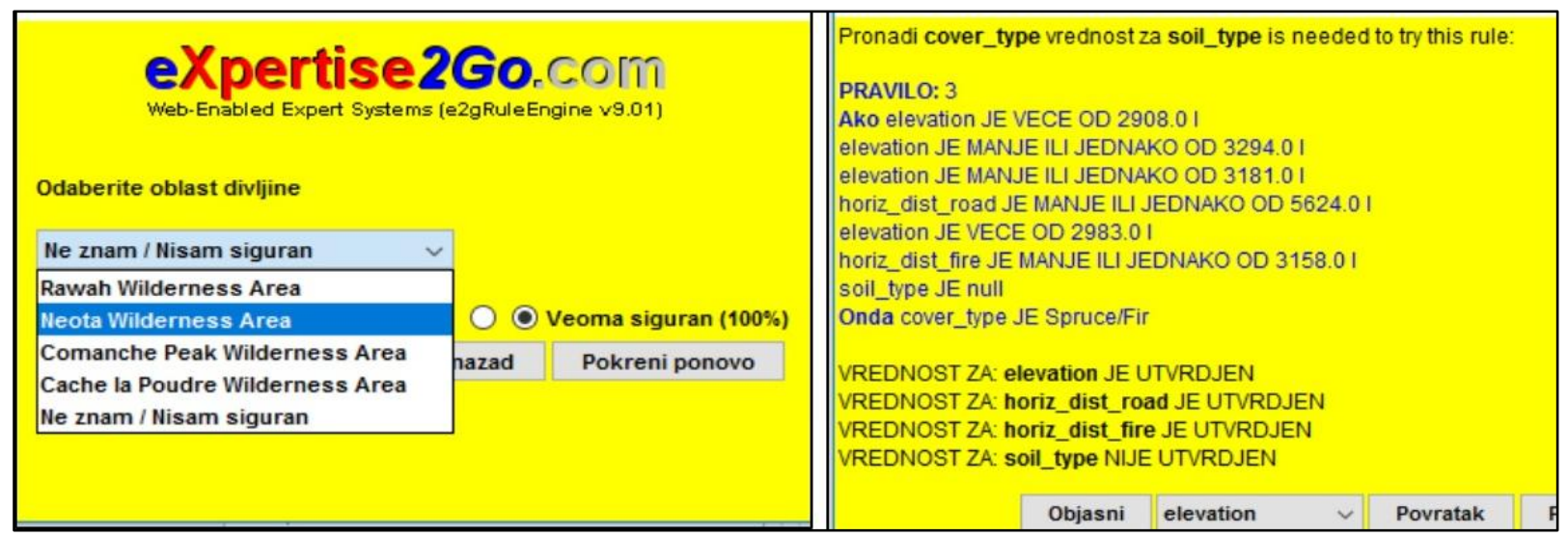

Figure 2. Some parts of the application that work in the web - HTML environment (with language customization 


\section{Conclusion}

An efficient way of creating a small Expert Decision Support System for the Android platform is shown without serious programming in the Java programming language. The knowledge base of the system, for given area of expertise was generated by inductive learning methods based on examples from the WEKA data research system, and the system was realized using the Expertise2Go and e2gDroid Lite Expert shell system for mobile devices.

Based on the given application area and a set of trained examples, specifically based on the Covertype DataSet qualification problem, was developed a support system for the decisions.

\section{References}

[1] UCI Machine Learning Repository. "Covertype DataSet". Center for Machine Learning Intelligent Systems - link: https://archive.ics.uci.edu/ml/datasets/covertype and (visited 17.12.2017.)

[2] Blackard J.A., Dean D.J. "Comparative Accuracies of Artificial Neural Networks and Discriminant Analysis in Predicting Forest Cover Types from Cartographic Variables", Computers and Electronics in Agriculture, Vol. 24. No.3, pp: 131-151, 2000.

[3] Blackard J.A., Dean D.J. "Comparative Accuracies of Neural Networks and Discriminant Analysis in Predicting Forest Cover Types from Cartographic Variables", Second Southern Forestry GIS Conference. University of Georgia. Athens, GA. pp. 189-199, 1998.

[4] Blackard J.A., "Comparison of Neural Networks and Discriminant Analysis in Predicting Forest Cover Types (Ph.D. dissertation)", Department of Forest Sciences. Colorado State University. Fort Collins, 1998.

[5] Oreški, D., Novosel, T. "Comparison of Feature Selection Techniques in Knowledge Discovery Process", TEM Journal, Vol. 3, No. 4, pp. 285-290, 2014.

[6] Gama, J., Rocha, R., Medas P. "Accurate decision trees for mining high-speed data streams“, Proceedings of the ninth ACM SIGKDD international conference on Knowledge discovery and data mining, pp.523-528, 2003.

[7] Giannella, C., Sayrafi, B. "An Information Theoretic Histogram for Single Dimensional Selectivity Estimation: Technical Report TR584“. Department of Computer Science, Indiana University Bloomington, 2005.

[8] Nikunj, C.O, Stuart J. Russell. "Experimental comparisons of online and batch versions of bagging and boosting", Proceedings of the seventh ACM SIGKDD international conference on Knowledge discovery and data mining, pp. 359-364, 2001.

[9] Obradovic, Z., Vucetic, S. "Challenges in Scientific Data Mining: Heterogeneous, Biased, and Large Samples: Technical Report", Center for Information Science and Technology Temple University, ch. 1, pp. 1-24, 2004.

[10] Miškovic, V., "Sistemi za podršku odlučivanju: Decision support systems“, Faculty of Informatics and Computing, Singidunum University in Belgrade, 2013.

\section{BIOGRAPHY OF AUTHORS}

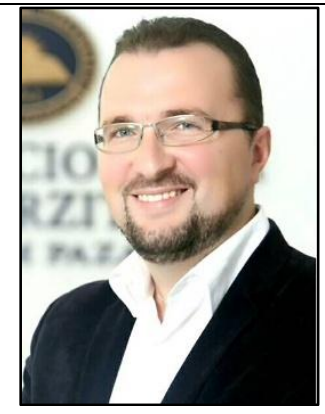

Muzafer Saračević (1984) - Associate professor of computer sciences at the University of Novi Pazar and dean of the Department of computer sciences at the same university. He defend bachelor thesis on Faculty of Informatics and Computing in Belgrade, master thesis on Faculty of Technical Sciences (University of Kragujevac) and 2013th year defend doctoral thesis on Faculty of Science and Mathematics (University of Niš). He specialized on Oracle academy in the field of database and programming. He is the author of over 130 professional and scientific papers, one monograph and two practicum. He is the author of one chapter in the scientific monograph of the international publisher. $\mathrm{He}$ is a member of the editorial board for five journals. 


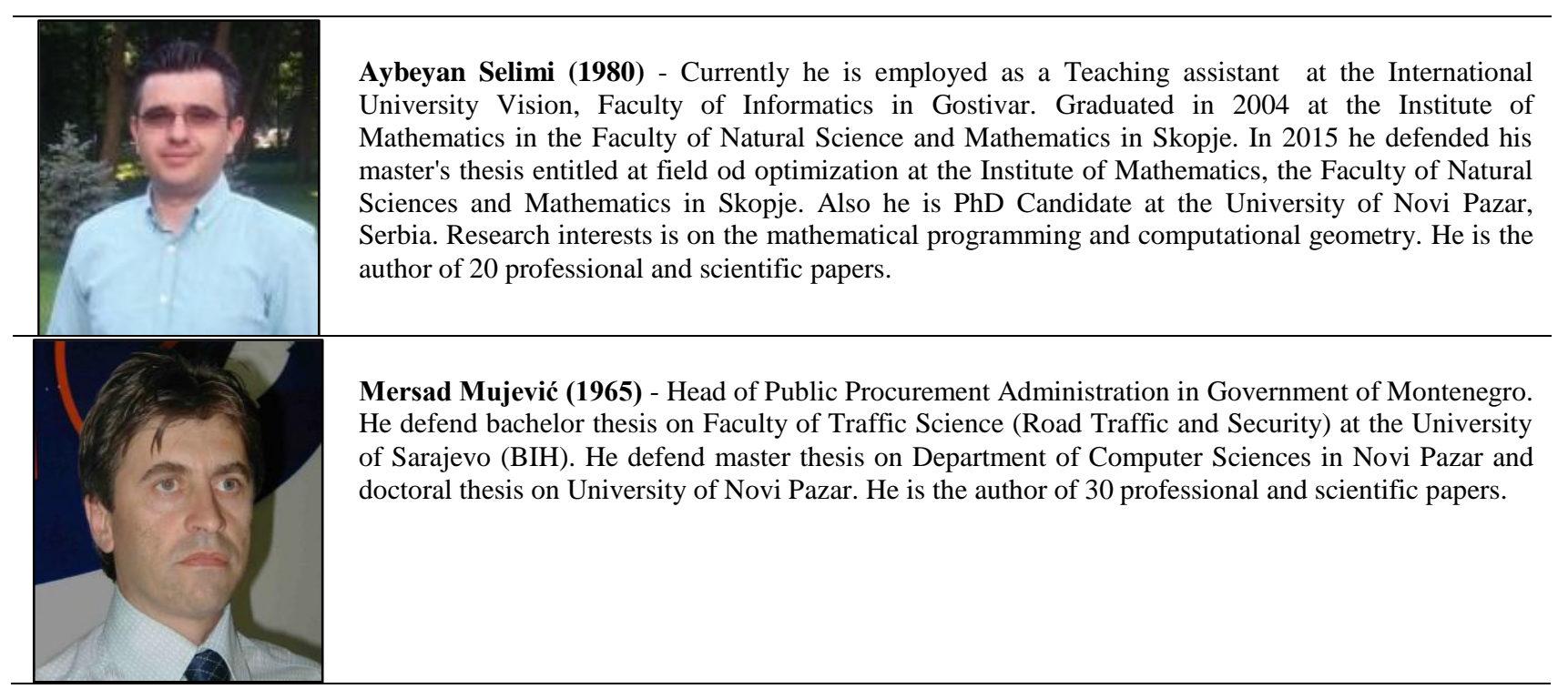

